\title{
Paracoccidioidomycosis and cryptococcosis with localized skin manifestations: report of two cases in the elderly*
}

\author{
Ederson Valei Lopes de Oliveira ${ }^{1}$ \\ Aline Turatti ${ }^{1}$ \\ Ana Maria Roselino ${ }^{1}$
}

\author{
Margarete Teresa Gottardo de Almeida ${ }^{2}$ \\ Ciro Martins Gomes ${ }^{1}$
}

DOI: http:/ /dx.doi.org/10.1590/abd1806-4841.20164061

\begin{abstract}
Distinct cases of Paracoccidioidomycosis and Cryptococcosis with atypical and localized skin manifestation on the upper limbs of two elderly patients are reported. In the 2nd one, he presented asymptomatic pulmonary cancer; the blood tests for fungal infection were negative, and the etiologic agents were seen in skin biopsy samples. This report emphasizes the importance of the differential diagnosis of infectious diseases in elderly patients.
\end{abstract}

Keywords: Aged; Carcinoma; Cryptococcosis; Granuloma; Paracoccidioidomycosis

\section{Case 1:}

A 79-year-old woman presented lesions similar to milia on the right upper limb for 2 months (Figure 1). Histopathological examination showed epithelioid granulomas with a suppurative center and serial sections confirmed fungal structures compatible with Paracoccidioidomycosis (PCM) (Figure 2). Chest x-ray, counterimmunoelectrophoresis for fungi and HIV serology were normal. She was treated with itraconazole, 200mg/day for 12 months, with remission.

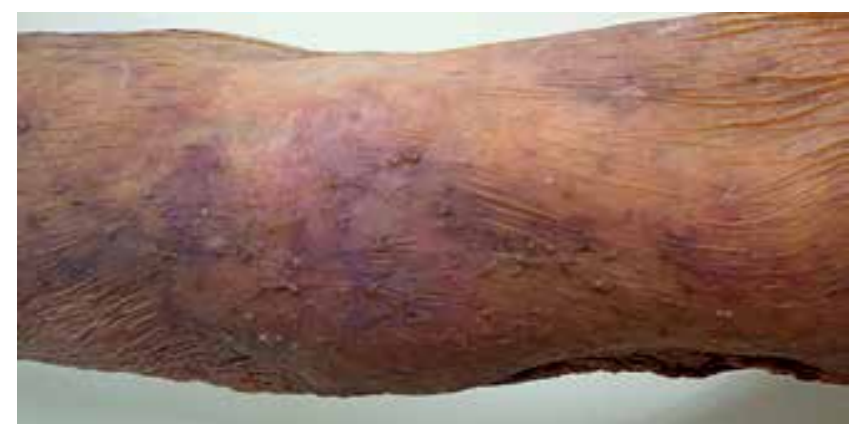

FIGURE 1: Yellowish papules similar to milia over an ecchymotic background on the right upper limb. On palpation, they were keratotic. Intense skin atrophy was observed

\section{Case 2:}

A 73-year-old man had a verrucous plaque on the left forearm for 2 years (Figure 3). Histopathological examination showed pseudoepitheliomatous hyperplasia and fungal spores permeating xanthomatous macrophages in the papillary dermis (Figure 4). Culture

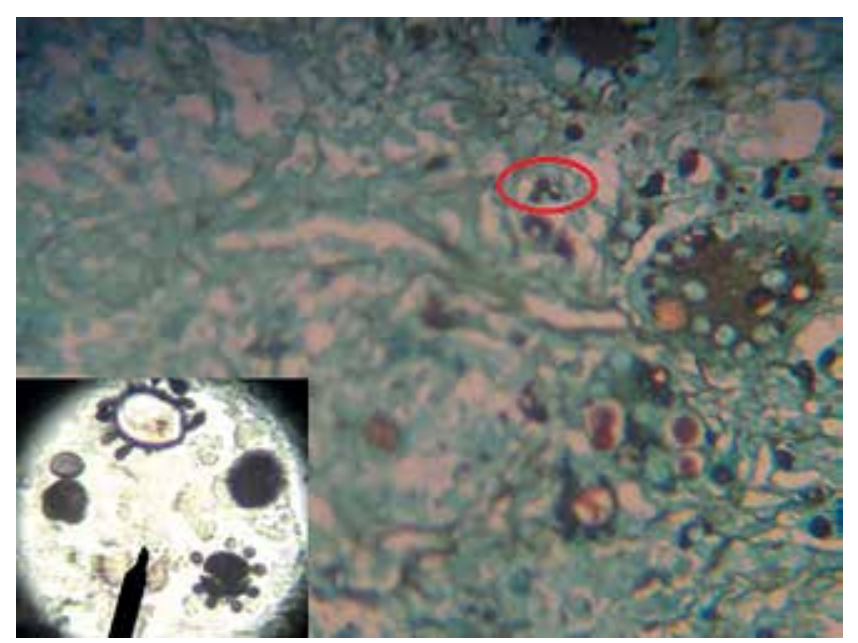

Figure 2: In the dermis, fungal structures with budding (Grocott staining). In detail, round corpuscles with multiple budding (100x)

Received on 21.09.2014

Approved by the Advisory Board and accepted for publication on 29.09.2015

Work performed at the Dermatology Division, Internal Medicine Department, Hospital das Clínicas de Ribeirão Preto, Faculdade de Medicina de Ribeirão Preto, Universidade de São Paulo (HCRP-FMRP-USP) - Ribeirão Preto (SP), Brazil. Financial Support: None. Conflict of Interest: None.

Universidade de São Paulo (USP) - Ribeirão Preto (SP), Brazil.

Faculdade de Medicina de São José do Rio Preto (FAMERP) - São José do Rio Preto (SP), Brazil.

(C2016 by Anais Brasileiros de Dermatologia 


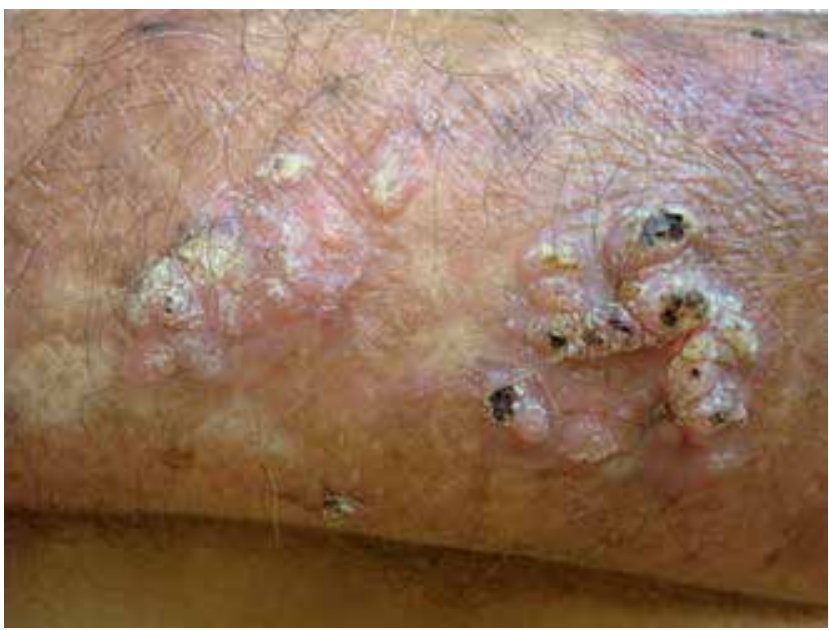

FIGURE 3: Verrucous plaques over an erythematous-infiltrated base, covered by blood crusts on the back of left forearm. Hypochromic cicatricial lesions and ecchymoses are also observed

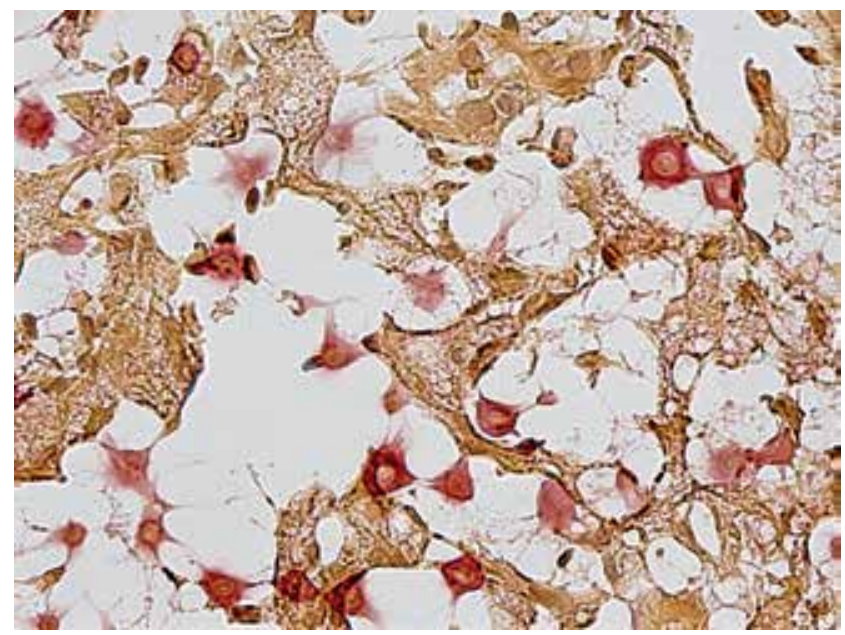

Figure 4: Mucicarmine stain showed a polysaccharide capsule suggesting Cryptococcus sp confirmed Cryptococcus neoformans. Liquor puncture, counterimmunoelectrophoresis for fungi and serology for HIV were normal. He was treated with fluconazole, $600 \mathrm{mg} /$ day for 2 months, with improvement. Chest tomography showed image of pulmonary neoplasm; patient died.

Lesions similar to milia are an atypical manifestation of PCM. In immunocompetent individuals lesions are localized, there is formation of granulomas with few fungi and low serum titles, as in case $1 .{ }^{1-4}$

In case 2, diagnoses of chromomycosis, tuberculosis, PCM, and squamous cell carcinoma must be considered. Due to thick polysaccharide capsule and low antigenicity of Cryptococcus sp., granulomas are not expected. Culture confirmed Cryptococcus neoformans, which presents neoformans and gattii varieties. The variety was not determined, however, gattii is common in immunocompetent individuals. ${ }^{5-6}$

It may be inferred that both patients presented probable predominance of Th1 response, justified by localized lesions, for no systemic involvement and no humoral response (negative serological tests) having been detected, and for positive response to antifungal treatment.]

\section{REFERENCES}

1. Parise-Fortes MR, Miot HA, Kurokawa CS, Marques MEA, Marques AS Immunology of paracoccidioidomycosis. An Bras Dermatol. 2011;86:516-24.

2. Medeiros VLS, Arruda L. Paracoccidioidomycosis sarcoidosis-like: immunological factors. An Bras Dermatol. 2013:88:120-3.

3. Shinkanai MA, Filho FQT, Mendes RP, Colombo AL, Moretti ML e Grupo de Consultores do Consenso e Paracoccidioidomicose. Consenso em Paracoccidioidomicose. Rev Soc Bras Med Trop. 2006;39:297-310.

4. Porro AM, Rotta 0 . Cutaneous and pulmonary paracoccidioidomycosis in a patient with a malignant visceral tumor. An Bras Dermatol. 2011;86:1220-1.

5. Moreira TA, Ferreira MS, Ribas RM, Borges AS. Cripitococose: estudo clínicoepidemiológico, laboratorial e das variedades do fungo em 96 pacientes. Rev Soc Bras Med Trop. 2006;39:255-8.

6. Nasser N, Nasser Filho N, Vieira AG. Criptococcose cutânea primária em paciente imunocompetente. A Bras Dermatol 2011;86:1178-80.

\author{
MAILING ADDRESS: \\ Ederson Valei Lopes de Oliveira \\ Av. Bandeirantes, 3900 \\ Campus Universitário Monte Alegre \\ 14048-900 - Ribeirão Preto - SP \\ Brazil \\ E-mail:edersonvalei@yahoo.com.br; \\ edersonvlo@yahoo.com.br
}

How to cite this article: Oliveira EVL, Almeida MTG, Turatti A, Gomes CM, Roselino AMF. Paracoccidioidomycosis and cryptococcosis with localized skin manifestations: report of two cases in the elderly. An Bras Dermatol. 2016;91(2):243-4. 